\title{
Analysis for SWOT-CLPV Matrix Model of Heilongjiang Provincial Skiing Industrial Development
}

\author{
Cheng Cao, Changhong Wang, Jianchang Ding \\ Physical Teaching Department of Mudanjiang Medical \\ University, Mudanjiang 157011 \\ Heilongjiang China
}

\author{
Guibin Su \\ Sports Science College of Mudanjiang Normal \\ University, Mudanjiang 157000 \\ Heilongjiang China
}

\begin{abstract}
On basis of numerously consulting information and investigations for Heilongjiang Provincial Skiing Ground, use SWOT-CLPV matrix model to conduct qualitative and quantitative analysis for current status of Heilongjiang skiing industry; Point out that advantages for Heilongjiang skiing industry are that it owns unique brand advantage and government's powerful dominant advantage; While its disadvantages lie in disadvantage of overall competitive strength for skiing ground, structural disadvantage for skiing industry and disadvantage for hardware facilities and software facilities which are critical factors affecting development level for Heilongjiang provincial skiing industry.
\end{abstract}

Keywords-Heilongjiang Province; Skiing Industry; SWOTCLPV Matrix Model; Analysis

Heilongjiang Province is one of provinces in China earliest developed ice-snow economy. From initial Icelantern Garden Party to Harbin Ice-snow Festival, then to Heilongjiang Provincial International Skiing Festival and China Harbin International Ice-snow Festival, through wisdom and diligence, Heilongjiang people melt severe cold as art, bestow ice and snow with life, create northern winter with a world full of ice and snow as golden season blending multi-field activities including culture, sports, tourism, economy and trade and science and technology, etc as a whole. China Heilongjiang International Skiing Festival established in winter of 1998 is not only important integral part of China Harbin International Skiing Festival, but also relatively separate important activity festival and it is an important historic mark for development of China's skiing and tourism industry. Heilongjiang Provincial International Skiing Festival has been held for fifteen sessions up to now which activity contents are more and more abundant attracting a large number of tourists to come to Heilongjiang for skiing. However, accompanied by problems occurred in development of skiing industry and fierce competition from other skiing markets from home and abroad, number of nonlocal tourists coming to Heilongjiang for skiing and tourism is being decreased year by year in recent years, and Heilongjiang provincial dominant and leading position in China's skiing market is being under threats and challenges and market share is being constantly declined [1].

\section{SWOT-CLPV MATRIX MODEL}

SWOT analysis method model (also called TOWS analysis method), namely trend analysis method, proposed by Management Professor Weihrich from University of San
Francisco in early 1980 s and often used for occasions including enterprise strategy formulating and competitor analysis, etc. This model of SOT-CLPV Theory is a model slightly modified on basis of SOT model [2]. Using this method can more objectively find out one's own internal advantage (superiority) and deficiency (disadvantage). After externally brought chance (opportunity) and threat are analyzed, analysis for interaction of these four factors will emerge four different trends and emerge different effects for enterprise's survival and development. These four trends are respectively: Superiority trend which is arose from combination of superiority and chance, conducive to rapid development for enterprise and owns leverage; Competition trend of vulnerability which is arose from combination of superiority and threat and reduces competitiveness of enterprise; Market trend of control which is arose from combination of chance and disadvantage and affects development of enterprise; Competition trend of problem which enables enterprise to face dilemma under joint effect by disadvantage and threat. The following $\mathrm{L}, \mathrm{V}, \mathrm{C}$ and $\mathrm{P}$ are respectively abbreviation for Leverage, Vulnerability, Control and Problem.

\section{ANALYSIS FOR SWOT-CLPV MATRIX MODEL OF HEILONGJIANG PROVINCIAL SKIING INDUSTRIAL DEVELOPMENT}

\section{A. Superiority of Heilongjiang Provincial Skiing Industry}

\section{1) Owning Superiority of Unique Brand}

In 1996, Harbin undertook $3^{\text {rd }}$ Asian Winter Games intercontinental winter comprehensive games held by China for the first time, which attracted eyes of compatriots and other Asian countries to Heilongjiang. Accompanied by completion of Yabuli Windmill Mountain Villa which is China's first large destination skiing holiday resort, prologue for rapid development of China's skiing industry was drew. In 1998, $1^{\text {st }}$ Heilongjiang Provincial International Skiing Festival created three firsts, namely, China's first international skiing festival, first skiing and tourism professional committee and first skiing club [3]. In 2009, $24^{\text {th }}$ World Winter Universiade is appraised by Kisllian, Chairman of FISU as "Harbin University Students Winter Games is the most successful session in history of University Students Winter Games!", which got the world's attentions and further upgraded influence of Heilongjiang ice-snow brand. In 2012, Yabuli Skiing Ground ranked first in China's $1^{\text {st }}$ Skiing Grounds Competitiveness Ranking List. 
Firsts one after another proved superiorities for Heilongjiang provincial ice-snow industrial brand and its position in China.

2) Owning Superiority of Abundant Ice-snow Resources Climate in Heilongjiang Province is temperate continental monsoon climate, winter is long and frigid and it is province with longest winter in China. Heilongjiang Province owns superiority of skiing resource richly endowed by nature, resource of ice-snow is widely distributed, quality of snow is good and it is province with most intensive resource of ice-snow in China. Unique geographical, natural and human resources have most important resource base for development of skiing industry.

\section{3) Unique Regional Superiority}

Heilongjiang Province is located in China's northeastern part, situated in geographic center of Northeast Asia and it is central zone for cultural, economic and trading exchanges in Northeast Asia. Both most northern pole and most eastern pole of China are within borders of Heilongjiang Province. Border line between Heilongjiang Province and Russia is $2981 \mathrm{~km}$ long, for which, Sino-Russian demarcation was fully completed in 2008 and 25 national first-class ports and 10 border trade zones exist here presently by which Heilongjiang Province owns special geographical superiority for development of Russian skiing and tourism [4]. In recent years, exchange and cooperation by Northeast Asian region are more and more frequent and develop toward high-level and multi-field direction. As central zone in Northeast Asia, tourism industry in Heilongjiang Province will be inevitably benefitted from this momentum of development [5].

4) Superiority of Deep and Diversified Regional Culture

Heilongjiang Province has numerous nationalities and owns unique superiority of resources including culture of Great Northern Wilderness, Red Culture and world-famous Daqing Petroleum Culture, while China's ice-snow art was just born in Heilongjiang Province, so ice-snow sports supports superiority of ice-snow culture with unique charm for Heilongjiang Province. There is only opening ceremony but not closing ceremony in China Harbin International Icesnow Festival held each year. It and Canadian Quebec Winter Carnival, Japanese Sapporo Snow Festival and Norway Oslo Skiing Festival jointly become the world's four festivals. It is currently the world's largest winter icesnow festival with longest time of activities.

5) Government's Powerful Dominant Superiority

Development for an industry is inseparable from governmental supports, Provincial CPC Committee, Provincial Government of Heilongjiang Province has taken development of tourism industry as entire provincial economic and social development strategy and scientifically plans and strongly promotes it. In May $2009,17^{\text {th }}$ session $7^{\text {th }}$ plenary meeting of Heilongjiang Provincial CPC Committee considered and adopted Planning for Heilongjiang Provincial Northland Scenery Characteristic Tourism Development Zone. Ten key construction plates are proposed in Planning, and detailed development planning is respectively formulated for them, while construction of taking Harbin city proper and Yabuli as core and "ice-snow summer capital · skiing paradise" as theme is one of them.

6) Superiority for Number of Skiing Grounds and Scale

Heilongjiang Province currently has owned nearly a hundred scale-ranging skiing grounds and it is in nationwide leading position in terms of owning quantity of skiing grounds. This year, 1 skiing ground is newly increased. Now, its total number of S-level skiing grounds reaches 30 ones with total number of 191 ski tracks, total length for ski tracks of $183.5 \mathrm{~km} \mathrm{[6].} \mathrm{Among} \mathrm{which,} \mathrm{skiing} \mathrm{grounds}$ represented by Heilongjiang Yabuli Skiing Ground, Yabuli Sunshine Holiday Village Skiing Ground (original Windmill Mountain Villa), Skiing Base of Harbin Institute of Physical Education and Harbin Jihua Changshoushan Skiing Ground have long been well-known in the world which have created golden skiing and tourism collection area centered by Harbin and five golden skiing zones.

\section{B. Superiority of Heilongjiang Provincial Skiing Industry}

\section{1) Superiority for Overall Competitiveness of Skiing Ground}

Compared with other provinces, Heilongjiang provincial nearly a hundred skiing grounds own greater superiority in terms of quantity and Yabuli Skiing Ground ranked $1^{\text {st }}$ in 2012 skiing grounds competitiveness ranking list. However, due to uneven development, unreasonable special layout enables overall competitiveness to be at disadvantage. Heilongjiang Provincial skiing grounds currently with $\mathrm{S}$ level are only 30 ones which number is less than $1 / 3$ of total number of all skiing grounds. Vast majority of skiing grounds are small ones and they appear many problems including small scale, less service facilities, incomplete safety facilities, poor management and services and both skiing equipments and skiing tools being used products, etc which result in weak overall competitiveness for Heilongjiang Province.

2) Superiority of Inputting Internal Capital and Attracting External Capital

Viewed from current investment situations for Heilongjiang provincial skiing industry, internal governmental investment share is greater, but share for investment of skiing industry by enterprises is less, compared with other regions, external investment attractiveness is insufficient and attracted external funds for skiing industry is less. Viewed from subject of investment, majority of Heilongjiang provincial large skiing grounds are invested and constructed by governments and managed by governments which typical representatives are Yabuli Skiing Ground and High Mountain Skiing Ground of Harbin Institute of Physical Education which are substantially different from those in Beijing, all skiing grounds in Beijing and its surroundings are of private nature [7]; Due to competition by other provinces, funds are invested to other developed large cities and their surroundings and attractiveness for Heilongjiang Province is being decreased [8], for instance, in Heilongjiang Province, only Melco Group invested CNY 1.5 billion to construct Skiing and Tourism Comprehensive Zone in Yabuli just in 2008, while 
in Chongli County, Hebei Province, 19 tourism projects with CNY one hundred million above were settled with total investment of CNY 22.651 billion just in 2012.

\section{3) Structural Disadvantage for Skiing Industry}

Firstly, phenomenon including unreasonable layout of skiing grounds, haphazard investments and unplanned lowprice repeated construction were serious. Taking Yuquan as an instance, only three local skiing grounds were initially operated, however, motivated by interests, ten more skiing grounds were established one after another within area of ten more square kilometers [9]. Numerous skiing grounds existed in the same area caused very serious vicious competition which not only affects entire skiing market, but also affects overall skiing brand image for Heilongjiang Province. Taking Pingshan Shenlu Skiing Ground as an instance, surrounded individual workshop type skiing grounds share forty thousand to fifty thousand person-time footfall from "Pingshan Shenlu" each year. Additionally, Heilongjiang Provincial skiing industry has not formed integral skiing industrial chain. Although several skiing apparatuses, equipments, skiing articles manufacturers have existed there, relatively compared domestic other types of enterprises, their competitiveness is weaker.

\section{4) Disadvantage for Cultivation of Local Skiing Market}

Cultivation targets for market of many large skiing grounds in Heilongjiang Province are outland tourists which often ignores cultivation for local markets within province. While scale and influence for Changchun Jingyuetan Vaasa International Off-road Skiing Festival in Jilin Province are being constantly expanded and professional-amateurcombination is also achieved: Not only professional athletes participated but also ordinary masses participated in serial activities for skiing festival [11]. As for training of university students off-road skiing, over 500000 persontimes of university students had been accumulatively trained in the past 8 years which had trained numerous fresh activists for China's off-road skiing [12]. Additionally, during winter each year, skiing grounds in Jilin Province provide venues free of charge to let over 20000 students in entire city be trained in rotation for four times [13]. However, although Heilongjiang has carried out activity of "Million Youngsters Stepping on Ice-snow" for over thirty years since its establishment, generally viewed, ice-snow sports activities were unsatisfactorily carried out in winter campuses and $58.8 \%$ of schools did not radically pour skiing grounds in 2010 [14]. Currently, although four skiing grounds in Heilongjiang Province are set with children dedicated skiing ground and actively organize winter camp activity, both scale and number of children are very small and activity of "Million Youngsters Stepping on Ice-snow" exists in name only.

\section{5) Disadvantage of Regional Natural Conditions}

In high-latitude region, long snowing period compare with other regions is originally superiority, however, it also objectively causes too low air temperature and it is too frigid which affects skiers' skiing quality and skiing experiences to some extent and brings certain effect on attracting skiers and tourists. Additionally, due to it is located in China's most northeastern part, for tourist outside this province, especially tourists from South China, skiing and tourism destinations in Heilongjiang Province belong to medium and far destinations, under circumstance of nationwide various regions constructing various kinds of skiing grounds one after another and higher transport costs are additionally needed for spending which is obviously at disadvantage. Furthermore, internationally, large skiing ground is generally constructed at an altitude of 2000$3000 \mathrm{~m}$ height, number of mountain masses which altitude close to $2000 \mathrm{~m}$ in Heilongjiang Province is very little which enables scale of construction for international skiing resort to be restricted by natural condition, while regional natural conditions for regions including tightly closed Jilin Provincial mountainous areas of Changbaishan Mountain and Xinjiang, etc are better than those in Heilongjiang Province.

6) Disadvantage of Hardware Facilities and Software Facilities

In terms of hardware facilities: Firstly, construction for transport network facilities in Heilongjiang Province is obviously lagged behind demands from rapidly developed tourism industry, transport networks are not very smooth and simultaneously grade of highways is lower which is not conducive to operation of tourists inside this province. Furthermore, most of hardware facilities of skiing grounds in Heilongjiang Province have relatively fallen behind, for instance, ropeways in many skiing grounds are still simply towed and skiing tools are used imported ones which safety rescue facilities are insufficient, and ancillary serving facilities for catering, etc are outmoded, simple and crude which causes low reception capacity and poor services quality.

In terms of software facilities: Firstly, because most of subjects for investment are of government behavior management model and also lasted administrative management model which management is inflexible, human relationship is more important than rules, and managerial talents and professional talents are obviously run off and phenomenon including practitioner operating without certificate and without qualification exist in individual skiing ground which enable skiing grounds to appear relatively lagged-behind problem no matter managerial philosophy or management system. Therefore, except for small part of large skiing grounds, management and reception services for skiing grounds in Heilongjiang Province have generally been not the first class, means and forms are single and use and utilization of modern information media are ignored, such as various kinds of media, ads and internets.

\section{Opportunity for Heilongjiang Provincial Development of Skiing Industry \\ 1) Rapid Development for Economy}

Rapid and stable development for China's economy is premise and basis for ensuring development of skiing industry. Viewed in accordance with development course of foreign skiing industrial great powers, development of their 
skiing industry is inseparable from rapid development for economy. Japan experienced a period of economic rapid growth in 1950 s to 1970 s, while it is just this period that Japanese skiing sports was rapidly developed. Development and expansion for skiing sports in Japan originated from Japanese economic development and social transform [15]. China's GDP growth rate is not lower than $8 \%$ since 2000, economy is always stably and rapidly developed, per-capita GDP is also rapidly increased, per-capita GDP had surmounted USD 3000 in 2008 and it had even reached over USD 10000 in Shanghai and Beijing. Economy for Heilongjiang Province is also under rapid development period, grow rate is higher than nationwide average level and it has been continuously grown by speed of double-digit percentage for successive ten years. It is just China's economic rapid development that has created unprecedented opportunities for development of skiing industry.

2) Transformation for Concept of Value

World Leisure Organization predicts that: Per-capita GDP achieving USD 2000 is threshold for growth of leisure demands; Vacation demand will generally occur when percapita GDP achieves CNY 3000 [16]. China's per-capita GDP had exceeded CNY 3000 in 2008, more people had long ago been restless on physical satisfaction, but paid more attention to and pursued spiritual satisfaction. More and more people start to focus on and select healthy lifestyle and thus are more willing to spend money on sports, leisure and entertainment which enable themselves to be healthy. Transformation for concept of value has facilitated many people to select modes including sports, vacation and travelling and consciousness of "returning to nature" is cherished for urban groups living and working under fast rhythm.

3) Rapidly Grown Skiing Population and Potential Skiing Consumption Market

In 1994, China's skiing population was 500 persons, most of which were professional athletes, news reporters and their relatives and friends. 1996 is starting point for rapid development of China's masses skiing, population for masses skiing was rapidly grown, to 2010, there were about 300 large, medium and small skiing grounds and stadiums where received skiers and visitors reached ten million person-times; Calculated by empirical probability, in case each skier averagely skis for two times in a snowing season, China currently approximately owns population of five million skiers and its is ten thousand times that of sixteen years before [17]. If skiing population and person-time are averagely annually increased progressively with speed of $10 \%$, in accordance with sixth census data on November 1 , 2011, China currently owns population of 1.34 thousand million, this illustrates that China's skiing population just accounts for $0.37 \%$ of nationwide population, compared with situations that about $10 \%$ of population participate in skiing each year in USA and Japanese and South Korean skiing population are respectively close to $13 \%-15 \%$ and $30 \%$ in their total population, this still appears considerable gap. Potential skiing market undoubtedly indicates inestimable attractiveness and driving force for development of China's skiing industry.

\section{Threats for Development of Heilongjiang Provincial Skiing Industry}

\section{1) Treats from Foreign Skiing Great Powers}

Rapid development of China's skiing industry also concerned by skiing grounds in foreign skiing great powers which vigorously promote their own country's high-end skiing grounds to China one after another. Mount Alps has been honored as "skiers' ultimate dream", more and more Chinese start to select going to Mount Alps area for skiing, to skiing paradise to experience extreme life and number of persons to Europe for skiing and travelling reaches 20000 persons each year [18]. Colorado State of USA and Whistler Mountain in Canada are famous scenic spots for skiing in North America and South Asian skiing tourist points should be Japan and South Korea. All large skiing groups in various skiing great powers enjoy very high reputation in skiing sports which are attracting more and more Chinese skiing enthusiasts for experiences.

2) Fierce Competition from Domestic Market

With rapid development of China's skiing industry, all other provinces and cities in China have also aimed at this "platinum" industry and skiing grounds are constructed out like spring bamboo shoots after rain. This industry has become current situation of groups of heroes scrambling for supremacy from Heilongjiang Provincial outshining others and holding palm. Nationwide has currently formed northeast, north, northwest and southwest relatively concentrated five regions and competition among regions and mutual competition within region are more and more fierce. Skiing grounds in Beijing region relying on stronger consumptive and stable Beijing visitor source are currently China's generally acknowledged skiing grounds gathering areas with strongest reception capacity, highest level of management and best operating efficiency. Beida Lake Skiing Ground and Jingyuetan Skiing Ground in Jilin have been powerful competitors for Heilongjiang Provincial skiing grounds. Experienced ten years of creation, "Changchun Savoie International Skiing Festival" settled in Changchun Jingyuetan has become boutique project for China's ice-snow tourism industry. Asian largest skiing ground - Wanda Changbaishan International Resort with investment of CNY 23 billion has been put into use. The rising star - Chongli in Hebei owns well-known skiing grounds including Genting, Wanlong, Saibei and Great Wall Ridge, it has proposed target of constructing China's top city of skiing and creating oriental "Davos" and skiing real estate industry is also under flaring rapid development. Currently, many more large skiing grounds are constructing and planning for construction in China in which there are at least over three projects with nearly $\mathrm{CNY}$ one hundred million.

3) Foreign-brand Treats for Skiing Articles and Skiing Equipments

Link of skiing apparatuses, skiing articles and skiing equipments among skiing industrial chain for Heilongjiang Province and even China is a currently very weak link which is just starting stage. Heilongjiang Province contains manufacturers who have emerged in producing skiing 
articles and skiing equipments and apparatuses, however, their domestic market shares are very small. Almost all equipments including snow pressing machines, snowmakers and ropeways, etc are imported, used snowboarders are not manufactured by Chinese enterprises and some ones used by small skiing ground are imported used products. Manufacturing of ski suits should be our superiority, however, market of skiing garments is still the world for imported brands, China's skiing garments manufacturers are basically practicing OEM, but without their own created brands.

\section{4) Problem of Low Conversion Rate for Skiing Population}

Now, many people are confused by rapidly grown skiing person-time, however, it can be seen from many investigations that annual skiing population is almost equal to skiing person-time. Vast majority of skiing person-times arose from experiencing skiers skiing for one time every snowing season, real skiing enthusiasts and ski-fanciers cover very small proportion and low conversion rate for skiing population is a big problem for current China's skiing industry. Currently, China's stable skiing crowd who can ski for 4-5 times within one snowing season is improbably more than 200000 and it is mainly concentrated in Beijing and northeast area, it can almost be negligible compared with skiing person-time by 10 million in one year and average annual conversion rate from 1995 to 2011 is just 2\% which gap is too big compared with $10-15 \%$ by skiing industrial developed great powers.

\section{E. Analysis of SWOT-CLPV Matrix Model}

Through above analysis for internal superiorities, disadvantages and external opportunities and threats for skiing industry in Heilongjiang and analysis of understanding conducted in accordance with status for current international, China's and Heilongjiang Provincial skiing industry. First put listed various factors and conditions into SWOT-CLPV matrix model (see which in Table I) and then analyzed four different trends arose from them, namely, superiority trend by " $L$ ", market trend of " $C$ " controlling playing of enterprise's superiority, competition trend of "V" reducing enterprise's superiority and competition trend of "P" with greater harm formed under joint effect by external threat and internal disadvantage.

On basis of analyzing internal conditions and external environment for Heilongjiang Provincial skiing industry, combine various factors in internal superiorities and disadvantages for Heilongjiang Provincial skiing industry respectively with various factors in opportunities and treats for external environment to form analysis table for two trends (see which in Table II and Table III). When different factors are combined, if they can form interactions and effects, mark them as corresponding trends. For instance, internal unique brand superiorities and opportunities for external economic rapid development of Heilongjiang Provincial skiing industry can interact and produce effect to form leverage superiority trend, therefore, they can be marked as L. While internal deep and diversified regional cultural superiorities and opportunities of external economic

rapid development are combined each other and cannot interact and produce effects, therefore, they are not marked. After various factors are combined and analyzed, the more trends for which factor by same trends combined with other factors, it illustrates that the greater this factor's effects are, and thereby biggest key factor affecting development of skiing industry in Heilongjiang can be analyzed and found out.

TABLE I. ANALYSIS OF SWOT-CLPV MATRIX MODEL FOR SKIING INDUSTRY IN HEILONGJIANG

\begin{tabular}{|c|c|c|}
\hline \multirow{11}{*}{$\begin{array}{l}\text { Internal Analysis } \\
\text { External Analysis }\end{array}$} & \multirow{11}{*}{$\begin{array}{l}\text { Superiority S } \\
\text { 1. Unique brand } \\
\text { superiority; } \\
2 \text {. Superiority of } \\
\text { abundant ice-snow } \\
\text { resources; } \\
\text { 3. Unique regional } \\
\text { superiority; } \\
4 \text { Deep and } \\
\text { diversified regional } \\
\text { cultural superiority; } \\
\text { 5. Governmental } \\
\text { powerful dominant } \\
\text { superiority; } \\
6 \text {. Superiority for } \\
\text { number and scale of } \\
\text { skiing grounds. }\end{array}$} & \multirow{11}{*}{$\begin{array}{l}\text { Disadvantage W } \\
\text { 1. Disadvantage for } \\
\text { overall competitiveness } \\
\text { of skiing grounds; } \\
\text { 2. Disadvantage for } \\
\text { inputting of capital and } \\
\text { attracting of internal } \\
\text { funds; } \\
\text { 3. Structural } \\
\text { disadvantage for skiing } \\
\text { industry; } \\
4 . \quad \text { Disadvantage for } \\
\text { training of local skiing } \\
\text { market; } \\
5 \text { Disadvantage for } \\
\text { regional natural } \\
\text { conditions; Disadvantage of } \\
6 \text {. Dacilities and } \\
\text { hardware fores } \\
\text { software facilities. }\end{array}$} \\
\hline & & \\
\hline & & \\
\hline & & \\
\hline & & \\
\hline & & \\
\hline & & \\
\hline & & \\
\hline & & \\
\hline & & \\
\hline & & \\
\hline \multirow{7}{*}{$\begin{array}{l}\text { Chance } \mathrm{O} \\
\text { 1. Rapid development } \\
\text { for economy; } \\
\text { 2. Transformation for } \\
\text { concept of value; } \\
\text { 3. Rapidly grown } \\
\text { skiing population and } \\
\text { potential skiing } \\
\text { consumption market. }\end{array}$} & & Control $(\mathrm{W}+\mathrm{O}=\mathrm{C})$ \\
\hline & & Overcoming \\
\hline & Leverage $(\mathrm{S}+\mathrm{O}=\mathrm{L})$ & Disadvantages \\
\hline & $\begin{array}{l}\text { Playing Superiority } \\
\text { and Using Chance }\end{array}$ & $\begin{array}{l}\text { Using Chances } \\
\text { Optimization and }\end{array}$ \\
\hline & $\begin{array}{l}\text { Core Brand Driving } \\
\text { Strategy }\end{array}$ & $\begin{array}{l}\text { Upgrading Strategy for } \\
\text { Industrial Structure }\end{array}$ \\
\hline & & Regional Combining \\
\hline & & Development Strategy \\
\hline \multirow{5}{*}{$\begin{array}{l}\text { Threat } \mathrm{T} \\
\text { 1. Threat from skiing } \\
\text { great powers; } \\
\text { 2. Threat from } \\
\text { domestic fierce } \\
\text { competition; } \\
\text { 3. Foreign-brand threat } \\
\text { for skiing articles and } \\
\text { skiing equipments; } \\
\text { 4. Problem of low } \\
\text { conversion rate for } \\
\text { skiing population }\end{array}$} & \multirow{2}{*}{$\begin{array}{l}\text { Vulnerability } \\
(\mathrm{S}+\mathrm{T}=\mathrm{V}) \\
\text { Using } \quad \text { Superiorities } \\
\text { and } \quad \text { Overcoming }\end{array}$} & \multirow{3}{*}{$\begin{array}{l}\text { Problem }(\mathrm{W}+\mathrm{T}=\mathrm{P}) \\
\text { Reducing Disadvantages } \\
\text { and Overcoming Threats } \\
\text { Optimization and } \\
\text { Upgrading Strategy for } \\
\text { Industrial Structure }\end{array}$} \\
\hline & & \\
\hline & Core Brand Driving & \\
\hline & & Regional Combining \\
\hline & 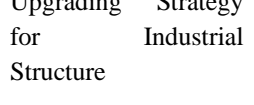 & Development Strategy \\
\hline
\end{tabular}


TABLE II.

ANALYSIS TABLE FOR LEVERAGE AND CONTROL TREND

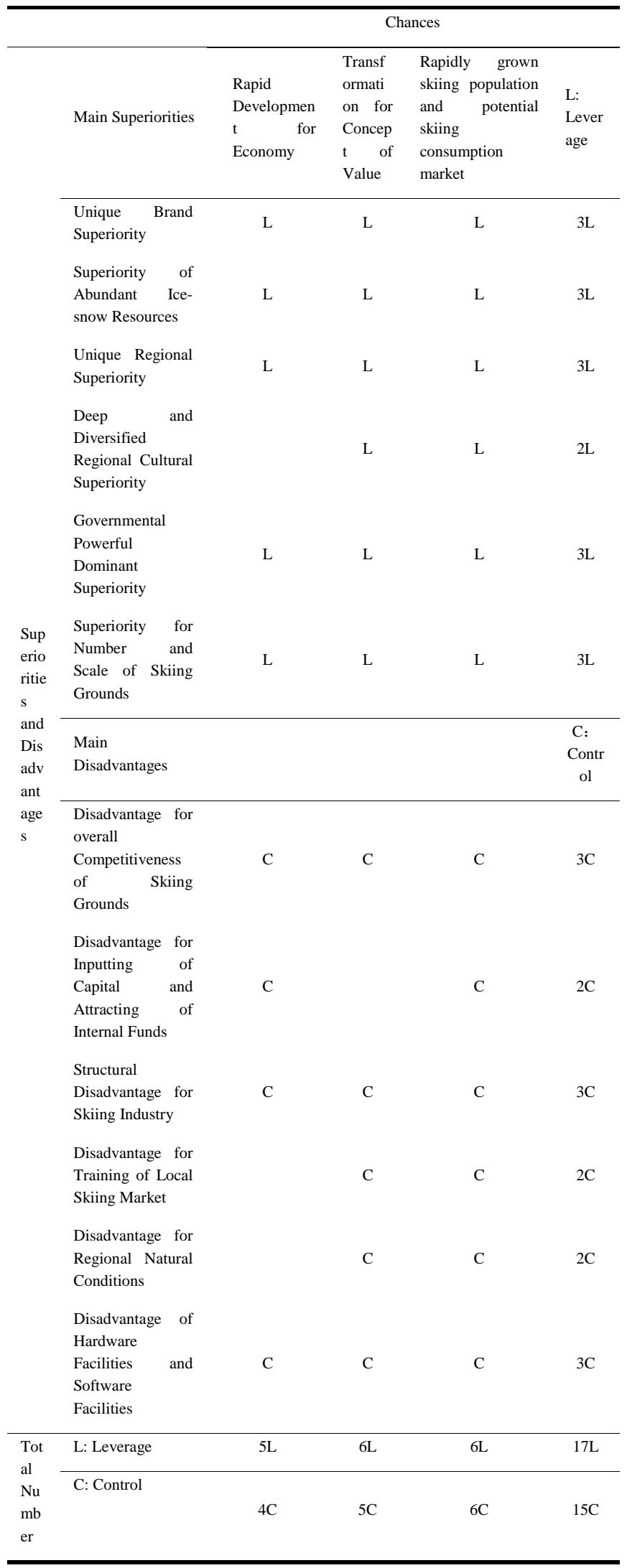

TABLE III. ANALYSIS TABLE FOR TREND OF VULNERABILITY AND PROBLEM

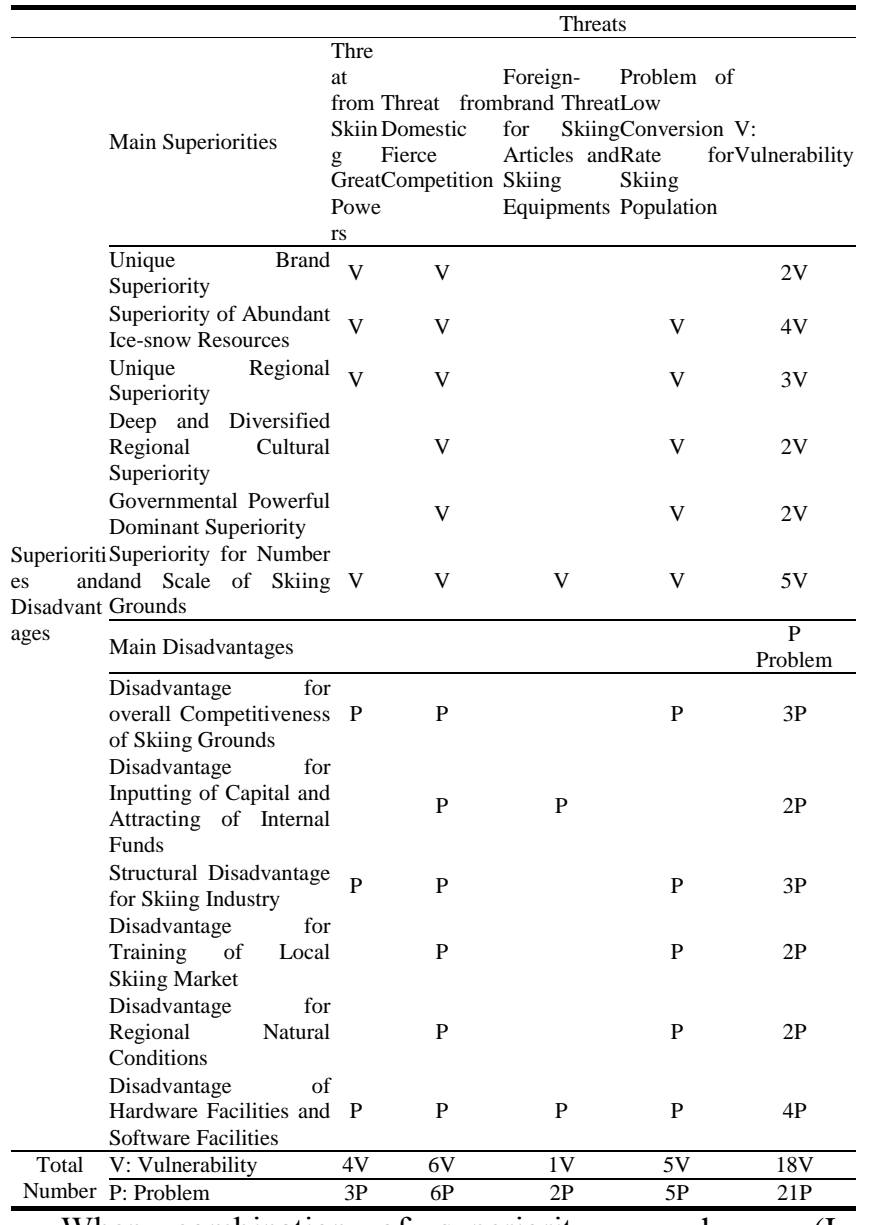

When combination of superiority - chance (L, Leverage) forms leverage superiority trend (see which in Table 2-2), skiing industry is rapidly developed, especially unique brand superiority, governmental powerful dominant superiority, superiority of abundant ice-snow resources and unique regional superiority occupy dominant position. In previous years, Heilongjiang Province fully seized favorable opportunities including national and governmental political supports, rapid development for economy, transformation for concept of value, rapidly grown skiing population and potential skiing consumption market and fully use our superiorities to enable Heilongjiang Provincial skiing industry to be at leading position.

When combination of disadvantage - chance $(\mathrm{C}$, Control) forms control market trend (see which in Table 22), disadvantage for overall competitiveness of skiing grounds, disadvantage of hardware facilities and software facilities and structural disadvantage for skiing industry are main factors restraining development of skiing industry. This requires us to implement key development, optimize investment environment, broaden financing channels, strengthen management mechanism and adjust and optimize the industrial structure to enhance and improve the overall competitiveness, transform disadvantages to superiorities 
and focus on development of skiing grounds to drive development for interrelated industries.

When combination of superiority-threat (V, Vulnerability) forms vulnerability competition trend (see which in Table 2-3), superiority for number and scale of skiing grounds displays most vulnerable and next ones are unique regional superiority and superiority of abundant icesnow resources when they are suffered external threats. While greatest external threat is fierce competition from domestic market and problem from low conversion rate for skiing population and threats by foreign skiing great powers are also main factors composing vulnerability trend. At this time, on basis of deeply excavating ice-snow resources and regional superiorities, we should actively develop market of tourist source for various aspects, consolidate our own superiorities, create boutique products, develop characteristic individualized skiing and traveling products and enhance our own market competitiveness to overcome threats.

When combination of disadvantage - threat ( $\mathrm{P}$, Problem) forms problem competition trend (see which in Table 2-3), it is the time for development of our skiing industry facing difficulties, fierce competition from domestic market and problem of low conversion rate for skiing population will be our faced main threats, while disadvantage for overall competitiveness of skiing grounds, disadvantage of hardware facilities and software facilities and structural disadvantage for skiing industry will become key factors obstructing smooth development for Heilongjiang Provincial skiing industry, among which, disadvantage for inputting of capital and attracting of internal funds, disadvantage for training of local skiing market and disadvantage for regional natural conditions will be reasons which cannot be overlooked.

\section{CONCLUSIONS}

Summing up analysis for Heilongjiang Provincial skiing industrial SWOT-CLPV matrix model and two trends diagrams and combining with understanding for international, domestic and Heilongjiang Provincial skiing industrial status, it can be discovered that, affected by external environment, Heilongjiang Provincial internally existed greatest superiorities are unique brand superiority and governmental powerful dominant superiority, while greatest disadvantages are disadvantage for overall competitiveness of skiing grounds, structural disadvantage for skiing industry and disadvantage of hardware facilities and software facilities. Heilongjiang Provincial skiing industrial leading superiorities have been currently in a critical situation. Control market trend and vulnerability competition trend shall be positioned which is reasonable. It will be ruthlessly eliminated in fierce market competition if it still considers itself to be flagship of the industry. In accordance with analyzed trends located in Heilongjiang skiing industry, development strategies which shall be adopted for Heilongjiang skiing industry are: Core brand driving strategy, optimization and upgrading strategy for industrial structure and regional combining development strategy

\section{REFERENCES}

[1]. Tang Yunsong · Studies on Countermeasures for Heilongjiang Provincial Skiing Industrial Development [D] · Harbin Engineering University, 2007.

[2]. Chen Maoqiang - SWOT-CLPV Theory and Application [J] - China Private Technology and Economy, 2005, 12:90-92.

[3]. China Heilongjiang International Skiing Festival · http://baike.baidu.com/view/4654393.htm

[4]. Zhang Guihai - Studies on Problems for Development of China's Skiing Industry [D] - Doctor Graduation Thesis of Northeast Forest University, 2008.

[5]. Planning for Heilongjiang Provincial Northland Scenery Characteristic Tourism Development Zone . http://wenku.baidu.com/view/9745ce6db8 4ae45c3b 358c51.html

[6]. Opening for 15th China Heilongjiang International Skiing Festival · http://www.hlj.gov.cn/zwdt/system/2012/12/13/010462863. shtml

[7]. Kan Junchang, Li Keliang and Wang Zijuan · Comparative Studies on Operating Status for Skiing Grounds in Heilongjiang Province and Beijing City and Their Surrounding Areas [J] A Academic Journal of Harbin Institute of Physical Education, 2008, 12:96-98.

[8]. Men Chuansheng - Studies on Sustainable Development for China's Skiing Grounds $[\mathrm{J}] \cdot$ Academic Journal of Shenyang Sport University, 2006, 25(1): 103-105.

[9]. Zheng Laifa and Tang Baosheng · Deep Development for Resources of Ice-snow, Sports and Tourism in Heilongjiang Province [J] · Icesnow Sports, 2010, 03:81-85.

[10]. Zhang Liangzhu - Studies on Affected Factors for Changchun IcesnowTourism Industry by Jingyuetan Vaasa Skiing Festival [D] · Northeast Normal University, 2011.

[11]. Cai Peiyu · [G/OL] Chinanews Network · http://www.chinanews. com /ty/2011/12-06/3512895.shtml

[12]. Wang Jing and Wu Dongying - Recreation of New Superiorities for Development of Heilongjiang Provincial Ice-snow Tourism - Comparison for Development of Ice-snow Tourism in North China [J] · Ice-snow Sports, 2010, 05:84-91.

[13]. Ma Rui, Liu Chunhua, Jiao Lei and Geng Xinshan · Studies on Launching of Heilongjiang Provincial Activity of "Million Youngsters Stepping on Ice-snow" [J] · Ice-snow Sports, 2011, 03:6569.

[14]. Hirakawa Nihiko - Trend of Sino-Japanese Skiing Sports [J] - Global Sports Market, 2010, 01:31.

[15]. Wang Liguo - Studies on Problems of Development for development of Northeast Skiing Industry [D] · Northeast Normal University, 2010.

[16]. Lu Jian . Process and Market Subdivision for China's Skiing Industry[G/OL] ·http://www.skiequipment.com.cn/FANGTAN/20116 21142951.html.

[17]. Tang Yunsong · Studies on Operation in China for Foreign-brand SkiingEquipments [J] Academic Journal of Beijing Sport University, 2009,v.3204:34-37. 